\title{
Urdimento
}

Revista de Estudos em Artes Cênicas

E-ISSN: 2358.6958

\section{A presença do riso na Capoeira Angola}

Renata de Lima Silva

José Luiz Cirqueira Falcão

Elderson Melo Miranda

\section{Para citar este artigo:}

SILVA, Renata de Lima; FALCÃO, José Luiz Cirqueira; MIRADA, Elderson Melo. A presença do riso na Capoeira Angola. Urdimento, Florianópolis, v. 2, n. 38, ago./set. 2020.

DOI: http:/dx.doi.org/10.5965/14145731023820200041

Este artigo passou pelo Plagiarism Detection Software | iThenticate 
Renata de Lima Silva²

José Luiz Cirqueira Falcão ${ }^{3}$

Elderson Melo Miranda ${ }^{4}$

\title{
Resumo
}

Neste artigo analisamos a presença do riso na roda de Capoeira Angola, utilizando como principais campos de análises o arquétipo do malandro e a ética da malandragem. O riso constitui-se num fenômeno sócio antropológico que instaura o humor e o cômico nos absurdos da existência e na percepção da inadaptação ou da distração particular do indivíduo em relação aos costumes sociais. No imaginário popular o arquétipo do malandro evoca esperteza, sagacidade e engenhosidade e é bastante enaltecido entre os angoleiros. A malandragem na Capoeira Angola é aqui discutida a partir da dimensão corporal, com ênfase no jogo, na brincadeira e especialmente no riso. Analisamos o transcurso da malandragem como algo que se consolidou no Brasil no início do Século XX e tem influenciado sobremaneira a prática da capoeira até os dias atuais.

Palavras-chaves: Malandragem. Capoeira Angola. Riso. Risível. Jogo.

The presence of laugh in Capoeira Angola

\begin{abstract}
In this article we analyze the presence of laughter in the roda of Capoeira Angola, using as main fields of analysis the archetype of the trickster and the ethics of trickster style. Laughter is a socio-anthropological phenomenon that establishes the humor and the comic in the absurdities of existence and in the perception of the personal maladjustment or distraction of the individual in relation to social customs. In the popular thinking the archetype of the malandro evokes cunning, wit and ingenuity, and is highly praised among the Angoleiros. The malandragem in Capoeira Angola is discussed here from the corporal dimension, with emphasis on the game, on the joke and especially on the laughter. We analyze the course of trickster style as something that was consolidated in Brazil at the beginning of the 20th century and has greatly influenced the practice of capoeira to the present day.
\end{abstract}

Keywords: Malandragem. Capoeira Angola. Laughter. Laughable. Game.

\footnotetext{
Este artigo é resultado de pesquisa que contou com o apoio financeiro do Conselho Nacional de Desenvolvimento Científico e Tecnológico - CNPq (Brasil), por meio do Edital MCTIC 28/2018

2 Profa. Dra. Curso de Dança, Programa de Pós-Graduação em Artes da Cena e no Programa de Pós-Graduação Interdisciplinar em Performances Culturais, da Universidade Federal de Goiás (UFG). Capoerista do Centro de Capoeira Angola Angoleiro Sim Sinhô. renatazabele@gamail.com

3 Prof. Universidade Federal de Goiás (Aposentado) - (UFG). Doutor em Educação pela UFBA. Mestre de Capoeira do grupo Beribazu. jlcfalcao@gmail.com

${ }^{4}$ Pós-doutorado no Programa de Pós-graduação Interdisciplinar em Performances Culturais da Universidade Federal de Goiás. eldersonmelo@gmail.com
} 
Gingar e malandrear são expressões do vocabulário coloquial brasileiro corriqueiramente utilizadas para representar ações humanas que gravitam em torno do lúdico e do cômico (riso e risível) e se manifestam de variadas formas. Por exemplo, a figura do malandro brasileiro, incorporada ao imaginário popular no início do século XX, é emblemática para expressar a esperteza, a sagacidade e a engenhosidade na execução de ações para a obtenção de vantagens em determinadas situações, conforme discutida densamente pelo antropólogo brasileiro Roberto DaMatta (1997). Igualmente, além do contexto brasileiro, temos como importantes referências de malandragem os personagens-tipo chamados de arlequins, presentes nas representações teatrais da Comédia Dell'Arte italiana, a partir do século XVI, que possuíam ações farsescas que movimentavam a dramaturgia teatral à época. (Barni, 2003).

Os malandros brasileiros do início do século XX e os arlequins da Comédia Dell'Arte movimentavam-se em relações sociais, numa constante adequação de gestos e atitudes que lhes garantiam transitar de um extremo social a outro, da invisibilidade ao reconhecimento, da pobreza à ostentação, sem que seus atos clandestinos fossem descobertos. Utilizavam-se de um certo jogo de corpo para transitarem de um lado a outro e, com inesgotável capacidade de adequação e readequação aos espaços sociais, movimentavam-se por meio de dobras culturais em busca de vantagens e benefícios.

Essa atitude de se mover de um lado a outro despertou uma disposição corporal própria da malandragem que foi incorporada à prática da capoeira em sua trajetória histórica numa relação dialética: os malandros criaram a capoeira a partir de seus corpos e a capoeira criou malandros a partir de suas técnicas e estratégias. Assim podemos pensar a malandragem como uma constituinte da capoeira e, ao mesmo tempo, como algo constituído a partir dela. Essa relação dialética entre malandragem e capoeira fica mais clara à medida que compreendemos os espaços sociais e simbólicos que a capoeira, uma manifestação cultural criada por africanos e seus descendentes no Brasil, ocupou desde meados do século XIX.

O jogo na capoeira caracteriza-se por uma constante negociação gestual em 
que simultaneamente cada jogador é desafiado pela imprevisibilidade dos golpes do oponente mediados pela ginga, numa dinâmica de complementariedade que imprime certa fluidez. Por mais que se pretenda minuciosa, a descrição dos procedimentos gerados num jogo de capoeira jamais refletirá a complexidade dos atos em si. Via de regra, não se efetiva um confronto direto, mas uma constante simulação de ações e reações fazendo com que o jogo, a dança e a luta se interpenetrem. "Através do jogo de capoeira, os corpos negociam e a ginga significa a possibilidade de barganha, atuando no sentido de impedir o conflito" (Reis, 1997, p. 220). Nessa luta dissimulada e disfarçada, o capoeira mais habilidoso é aquele que mostra que pode acertar um golpe mais não o faz, e com isso, possibilita a continuidade do próprio jogo. (Falcão, 2004).

Além da ginga, o jogo na Capoeira Angola é constituído de ataques, defesas e floreios que incrementam sua plasticidade. Os ataques mais usuais são rabo de raia, meia lua de frente, meia lua de costas, chapa, cabeçada e possíveis variações destes. As defesas variam entre negativas, rolês e saídas do "jeito que o corpo dá"5. Para a execução dos golpes se prioriza o uso dos pés e da cabeça e se evita ao máximo o usa das mãos para esse fim, todavia, as mãos são fortemente utilizadas como apoio do corpo no chão, já que o jogo de Capoeira Angola valoriza a movimentação nos níveis espaciais médio e baixo. Entre os floreios e movimentos acrobáticos estão os aús, bananeiras e meneios de corpo que cada capoeirista insere em seu jogo.

A malandragem se constituiu como um dos principais ingredientes de um jogo, que, no contexto ritualístico da roda de capoeira, é considerado envolvente. DaMatta (1997) destaca que o malandro é um sujeito que dribla as regras sociais e expressa a sua individualidade pelo modo de andar, de falar, de se comportar ou de vestir-se. Eternizado no mundo do samba e presente em outras manifestações da cultura popular brasileira, o malandro geralmente aparece como um tipo paradigmático ou herói. Para o referido autor, se aceitarmos o fato de que as sociedades são diferentes porque em cada formação social um certo número de dramas se materializa com regularidade, pode-se dizer que dessas dramatizações

${ }^{5}$ Expressão recorrente no discurso do Mestre Plínio, do Centro de Capoeira Angola Angoleiro Sim Sinhô. 
regulares emergem personagens típicos recorrentes, como é o caso do malandro.

Há muitas evidências de que a Capoeira Angola se consolidou como manifestação cultural acompanhando o discurso sociológico da malandragem. Ela é defendida por seus praticantes como um jogo de malandragem, o que quer dizer de esperteza, vivacidade, astúcia e "jogo-de-cintura”. Também chamada de "malícia” ou mesmo de "mandinga" (Silva, 2004), a malandragem pode aparecer na capoeira de diversas formas, como por exemplo: na performance daquele sujeito habilidoso capaz de passar uma rasteira no camarada e o colocar no chão sem que este se dê conta do que aconteceu, e ainda, faceiramente, abrir um sorriso e, num gesto de cortesia, estender a mão.

No contexto deste artigo, a malandragem é analisada a partir da dimensão corporal, em que o jogo, a brincadeira e o riso preponderam. Para isso, levamos em consideração o que asseverou Salvadori (1990) sobre o fato de os malandros cariocas (capoeiras e outros) terem divulgado por intermédio de suas expressões corporais e musicais, suas críticas ao horror do trabalho disciplinado, acenando para formas mais autônomas e menos disciplinadas de sobrevivência, em que se valorizavam a boemia, a festa e o ócio.

A metodologia utilizada neste trabalho privilegia principalmente a experiência dos autores com a prática da capoeiragem e a relação orgânica com os campos de estudos das Performances Culturais e do Teatro. Nesse sentido, é importante salientar que as sínteses apresentadas são decorrentes não somente da verificação de hipóteses, mas também de uma intensa imersão no campo, que se apoia na ideia de que os saberes são confluências advindas de vivências, percepções e reflexões construídas não apenas a partir de pressupostos teóricos, mas também no/pelo/com o corpo e na/pela/com a cultura.

\section{A Edificação de uma determinada "Malandragem" na Capoeira}


Que aquela tal malandragem não existe mais.

(Chico Buarque. Homenagem ao Malandro. LP Ópera do Malandro, 1978).

Ao longo de sua trajetória histórica, a capoeira se desenvolveu predominantemente, no contexto urbano da rua. Em um livreto sobre sua vida, o saudoso e irreverente Mestre Canjiquinha (1925-1994) proclamou que ele "era do tempo em que capoeira, filosofia e putaria são aprendidas na rua" (in: Moreira, 1989, p. 3). Foi, portanto, na rua, utilizando o corpo como principal instrumento das relações socioculturais, onde o capoeirista edificou sua malandragem, na encruzilhada da "fome com a fama" (Abreu, 2003, p. 14). Isto é, entre a exploração a qual o povo negro, e as classes populares em geral, foram submetidos e a sua criatividade como tática de enfrentamento a esse processo, em plena alvorada da urbanização brasileira, no final do Século XIX e início do Século XX, sobretudo nas cidades do Rio de Janeiro e de Salvador.

Entre portos, becos, vielas, prostíbulos, feiras e festas o malandro se destacava nos sambas e em outras manifestações de rua. Uma pessoa que combinava as características de um sujeito descolado, folgado, esperto, de índole duvidosa, com a de uma figura sedutora, que tinha jogo de cintura e que se preocupava com a sua imagem e a sua moral ${ }^{6}$. Embora a malandragem fosse uma característica dos capoeiristas de meados do século XIX até o primeiro quarto do século $X X$, não se pode dizer que ela se configurava a partir de um perfil único. $A$ partir das discussões sobre malandragem de DaMatta (1997), das considerações de Abreu (2003) sobre a presença da malandragem na capoeiragem no final do século XX na Bahia e, ainda, considerando nossa experiência com a prática da capoeira, fortuitamente permeada por relatos, narrativas e memórias dos mestres considerados antigos, podemos inferir que neste período histórico havia inúmeras maneiras malandras de ser. Entre ariscos e sedutores, valentões e fanfarrões, a malandragem foi delineando certa corporeidade e maneira de ser, além de se constituir como uma questão sociológica para melhor se entender a sociedade

${ }^{6}$ Moral, no vocabulário dos capoeiras da primeira metade do Século XX era um termo frequentemente utilizado para designar honra, poder e representatividade. 
brasileira.

Os sujeitos do cotidiano das classes populares da capital do Império que cultivavam a figura do malandro foram rapidamente incorporados no imaginário social e, em alguns casos, eternizados em grandes clássicos da literatura brasileira. Como por exemplo o Chico-Juca da obra Memória de um Sargento de Milícia, de Manuel Antônio de Almeida, publicada em 1852. Chico-Juca era um profissional da desordem, "afamadíssimo e temível", um tipo que despertava a atenção por onde andava.

Chico-Juca era um pardo alto, corpulento, de olhos avermelhados, longa barba, cabelo cortado rente; trajava sempre jaqueta branca, calça muito larga nas pernas, chinelas pretas e um chapelinho branco muito à banda; ordinariamente era afável e gracejador, cheio de ditérios e chalaças, porém nas ocasiões de sarilho, como ele chamava, era quase feroz. Como outros têm o vício da embriaguez, outros o do jogo, outros o do deboche, ele tinha o vício da valentia; mesmo quando ninguém lhe pagava, bastava que the desse na cabeça, armava briga, e só depois que dava pancadas a fartar é que ficava satisfeito; com isso muito lucrava: não havia taberneiro que the não fiasse e não o tratasse muito bem. (Almeida, 1997, p. 56-57).

Dentre tantos atores da cultura popular brasileira que encarnaram a figura do malandro chama a atenção o Seu Zé Pelintra. No Rio de Janeiro foi considerado um "malandro divino" que transitou entre a boemia, o misticismo e a religiosidade afro-brasileira. Como mito, caiu no gosto do povo e se tornou uma espécie de embaixador das populações marginalizadas que viviam na rua (Ligiéro, 2004). Hoje, pode ser visto bebendo e fumando em diferentes terreiros de umbanda e de religiões correlacionadas.

Segundo Zeca Ligiéro (2004, p. 64), Zé Pelintra se tornou também patrono da capoeiragem, “[...] pois muitos exus de seu grupo teriam pertencido às rodas de malandragem da antiga Lapa, no Rio de Janeiro: Zé Malandro, Terno Branco, Camisa Preta, Carioquinha, Zé Pretinho, Gargalhada e Zé das Mulheres formam o mitológico 'reino da malandragem”.

Um outro exemplo de símbolo da malandragem foi o singular Madame Satã (José Francisco dos Santos, 1900 - 1976) que circulava pela Lapa carioca em meio à malandragem, defendendo a si e a outrem com a malícia da capoeira. Satã ficou 
conhecido por sua história de valentia e por ser assumidamente homossexual e se travestir.

A malandragem, que também perpassava o samba e outras práticas culturais, acentuou o sentido de vadiação na capoeira, facilitando o seu vínculo aos contextos festivos, como por exemplo, as festas de largo em Salvador, conforme comenta Frede Abreu (2003, p. 34):

[...] durante as décadas de 40, 50 e 60 do século anterior [XX], no domingo, o mais alegre dos dias, um rito profano se tornou um vício sagrado para muitos capoeiristas baianos: vadiar na Liberdade, no Barracão, no terreiro, na roda de Waldemar. Era a "vadiação", palavra maldita pela crônica policial, sinônimo de contravenção, que se tornou predileta e significativa para os capoeiristas e sambistas denominar as 'funções' de sambar e capoeirar.

Como destaca Dias (2006, p. 169), transitando entre a ordem e a desordem, "os capoeiras de outrora 'soltavam a mandinga' tanto nas rodas de capoeira quanto na roda da vida". Essa mandinga fazia parte das práticas sociais malandras que povoavam o cotidiano das ruas, como a capoeira.

Se por um lado a malandragem é caracterizada pelo ato e efeito de seduzir e enganar, a mandinga, por seu turno, está mais diretamente relacionada com contribuições e simbolismos africanos atados aos sentidos de segredo e mistério. Pode-se referir a feitiços e encantamentos utilizados para a proteção e a obtenção de benefícios diversos. Por vezes, o ato de proteger-se implica em não deixar que outrem the atrapalhe. No contexto da capoeira as noções de malandragem e mandinga são associadas praticamente como sinônimos que se imbricam para resultar em um ingrediente especial que o capoeirista precisa conquistar para adquirir respeitabilidade e ser considerado um "bamba".

A “malandragem da mandinga”, expressão utilizada aqui para retomar a tese de Dias (2006), representa em tempos hodiernos uma expectativa de jogo de capoeira, sobretudo no contexto da Capoeira Angola. Por outro lado, existe um entendimento de que nem todo capoeirista é necessariamente um mandingueiro ou malandro, mesmo que se admita o fato de que a prática da capoeira contenha 
em si a potência da malandragem.

No alvorecer do século XXI ainda tivemos a oportunidade de encontrar nas rodas de capoeira velhos capoeiristas que consolidaram seus aprendizados da malandragem nas ruas, entre o conflito e o lúdico, isto é, antes do processo massivo de escolarização da capoeira. Na verdade, eles se tornaram grandes referências e elos importantíssimos entre a geração "dos valentão", como frequentemente dizia Mestre João Pequeno de Pastinha (1917-2011), e a nova geração de mestres formados a partir de outras referências.

A partir do fenômeno da criação de escolas de capoeira, a figura do malandro vai paulatinamente perdendo espaço e organicidade. O perfil esperado dentro desses contextos formais de ensino da capoeira passa a ser o de uma figura enquadrada dentro de um determinado ethos social. Com isso, a capoeira vai se afastando gradativamente das ruas e ocupando espaços privados com o objetivo de ganhar respeitabilidade social e ser desassociada dos "baderneiros" e dos "valentões".

Mestre Pastinha, entre outros importantes líderes da Capoeira Angola, foi fundamentalmente um pedagogo que acreditava que todos poderiam aprender a arte da mandinga, "general, também doutô" (Mestre Pastinha). Com seu espírito devotado, formou vários capoeiristas que dariam continuidade ao seu legado. Em uma de suas célebres frases, afirma: "a esses rapazes ensinei tudo que sei, até o pulo do gato" (in: Muricy, 1998) deixando escapulir, ao se referir a João Grande e a João Pequeno, que até mesmo o ingrediente especial da capoeiragem, já identificado por nós como mandinga, malandragem, que pode ainda ser denominado como dendê, poderia ser adquirido através de um processo pedagógico.

Por outro lado, Mestre Pastinha também reconheceu, e deixou isso registrado em seus conhecidos manuscritos, que "cada um é cada um e ninguém joga do meu jeito", admitindo que, apesar de o processo de formação do capoeirista depender da intervenção de um mestre, existe nesse aprendizado uma parcela de subjetividade que propicia e garante espaço para a afirmação individual. 
Nesse contexto, consideramos que ocorreu um processo que estamos denominando de "escolarização da malandragem" que pode ser sintetizado na seguinte ideia: Se no final do século XIX e início do século XX a malandragem era um condição agenciada por um contexto sociocultural e econômico, que rendia à capoeiragem estética e estratégias determinadas, a partir da segunda metade do século XX, a malandragem na capoeira passa a ser, em grande parte dos casos, um aprendizado que se adquire na própria prática e que se estende para outras dimensões da vida. Em outras palavras, o lugar da aprendizagem da malandragem se inverteu. Se antes os capoeiristas levavam a malandragem da rua para a roda, atualmente essa malandragem é aprendida na roda e levada para a rua(vida).

Como vimos, em determinado período da história, o caráter de vadiação e de boemia garantiram que a roda de capoeira fosse também um lugar do lúdico, da brincadeira e da festa. A partir do fenômeno da escolarização da malandragem, qual seria o lugar do riso nas rodas de Capoeira Angola na contemporaneidade?

\section{Considerações sobre o Riso}

Segundo Bergson (2007), tal como a linguagem e a inteligência, o riso é uma expressão tipicamente humana. Ele assinala que rimos porque somos humanos. Nesse caso, o riso é um fenômeno socioantropológico que integra a experiência humana, cuja característica central é possuir dois componentes indissociáveis: um objeto/sujeito/situação risível e um sujeito que ri.

Para Alberti (2011), existem diferentes tipos de riso, produzidos por variadas situações risíveis, possíveis de se organizar em duas categorias: o humor e o cômico. A primeira, presente, por exemplo, na piada e no chiste, representa um riso que se processa a partir da percepção intelectual das contrariedades lógicas do objeto risível, ou seja, manifesta-se a partir do prazer advindo do entendimento de uma situação eminentemente contraditória da realidade. No segundo caso, o riso cômico, presente, por exemplo, no deboche, na sátira, nas ações de palhaços, o objeto risível encontra-se na percepção ilógica da realidade, nos absurdos da existência, na capacidade humana de deslocar os sentidos das coisas, por meio 
do jogo.

Sobre o assunto, o filósofo brasileiro José Thomaz Brum (2008, p. 57) argumenta que:

\begin{abstract}
Apesar de existir um tipo de cômico cerebral que se atém apenas as "contrariedades lógicas" (humor inglês), existe também uma espécie de "riso louco", desmedido, revelador dos absurdos (risíveis) da vida. Novamente é Stendhal quem nos orienta: a sátira (Stendhal se refere aqui a Molière), com sua obsessão pela crítica, é inferior ao "riso alegre" que é conduzido por "uma imaginação louca que nos faz rir como uma criança". O riso provocado pelo cômico passeia, assim, pelo mundo das aparências e zomba, de maneira despreocupada, das supostas profundidades da existência.
\end{abstract}

Protagonista de distintas expressões culturais, tais como a comédia do teatro ocidental, ou manifestações carnavalescas analisadas por Bakhtin (2013) em seus estudos sobre a cultura popular na Idade Média, o riso brota perante situações de transbordamento de alegria proveniente da percepção da inadaptação ou da distração particular do sujeito em relação aos costumes sociais.

Se por um lado, as situações trágicas e dramáticas são produtos de experiências humanas decorrentes das convenções e valores sociais tais como são, por outro, o riso e o risível decorrem do lúdico e da deformação de hábitos, costumes e convenções. (Pavis, 1999).

Nessa acepção, o riso e o risível aparecem em distintas culturas como componentes da capacidade humana de observar ou provocar a degeneração de modos de vidas, de relações sociais e culturais, transformando situações negativas da vida por meio de potências criativas.

O riso evidencia a condição incompleta, não divina e vulnerável da vida, e traz para o sujeito o ato e o efeito por saber-se inacabado, incompleto, deslocado, isto é, perceber-se como alguém momentâneo, sem nenhuma ideia de alcançar a perfeição ou o acabamento eterno.

O riso tem sido largamente explorado no teatro desde a Idade Média com os bufões e os bobos da Corte. Estes provocavam o riso com suas atuações, construídas a partir de um tipo característico grotesco, blasfêmico e sagaz. 
Perpassando pela Commedia Dell' arte, o riso ganha destaque especial em personagens mascarados que acentuavam determinadas características humanas disformes por meio da trapaça e da farsa.

Figuras históricas atribuídas à função de fazer rir são os palhaços e/ou clowns ${ }^{7}$, por meio de suas ingenuidades e de suas maneiras desajeitadas de relacionar-se com as situações do cotidiano. São arquétipos de figuras humanas desastradas, dos tipos desajustados, errados e simplórios. Pantano (2007, p. 39) relata que a origem do palhaço está diretamente relacionada com a queda:

\begin{abstract}
Augusto, o idiota, surgiu quando Tom Belling, um cavaleiro inglês, caiu no meio da pista de um circo. Ao perceber que a queda tinha sido causada por sua embriaguez, o público não se conteve e extravasou toda a sua alegria diante de seu ar bobalhão e de seu nariz vermelho.
\end{abstract}

A situação acima exposta explica também a origem do nariz vermelho do palhaço, que se machucou na queda. Nessa perspectiva, a figura do palhaço se constitui por meio de um estado que inclui os desastres corriqueiros, por exemplo, a predisposição para a queda por meio do desequilíbrio provocado pela embriaguez.

O palhaço não se apega com a virtuose dos movimentos e sim com a falha na execução dos mesmos. Cria sempre uma situação que aparentemente lhe produziria uma satisfação, mas que, na verdade, the conduzirá ao erro. É justamente a falha que faz com que o público se identifique com as características do palhaço, pois se aproxima da imperfeição humana.

Diferentemente do palhaço, inserido no reino do cômico, o capoeira tem uma nítida preocupação com a especialização técnica para demostrar habilidade na execução das ações. Como pudemos verificar anteriormente, tais técnicas foram construídas a partir de uma concepção malandra de vida que se consolidou, em alguma medida, na corporeidade e no jogo da capoeira e que pode ser verificada

\footnotetext{
7 O termo palhaço deriva do italiano paglia, que significa palha. Essa expressão refere-se, justamente, ao tipo de material usado inicialmente para a confecção de suas vestimentas. A palavra clown deriva do inglês clod, que se refere ao camponês e sua ligação com a terra. De origem no circo e na pantomima inglesa, ambos os termos se referem a figuras cômicas constituídas a partir de brincadeiras e atuações populares.
} 
em figuras cômicas.

É importante considerar, contudo, que o malandro, embora possa se aproximar do cômico, devido seu deboche social, não poderia de forma alguma ser confundido com um palhaço ou outra figura cômica (bufão, bobo da corte, arlequim etc.), cujo propósito exclusivo é a alegorização da vida e a provocação do riso.

Embora o capoeira não pretenda provocar o riso como um palhaço, indubitavelmente se coloca em situações capazes de gerá-lo, já que este se manifesta de forma espontânea em muitas instâncias da vida cotidiana. O riso se faz presente na brincadeira, na queda, na zombaria, no fracasso e no erro, situações que fazem parte do jogo de capoeira.

Se no campo do Teatro e do Circo, um conjunto de técnicas e de treinamentos foi desenvolvido para acionar o riso, como isso acontece na roda de capoeira? Apenas de forma espontânea? Ou também por meio de códigos próprios, na perspectiva do que aqui estamos chamando de escolarização da malandragem?

\section{O Riso na Capoeira Angola}

A roda de capoeira e o teatro se constituem em performances culturais que apontam para várias características em comum, como o fato de serem eventos extraordinários, isto é, que instauram um espaço-tempo extracotidiano. Tal como no teatro cômico, a roda de capoeira, sobretudo da Capoeira Angola, pode se configurar como um local no qual o riso pode ser acionado, tanto a partir de dispositivos casuais e espontâneos, como a partir de convenções próprias. Todavia, é importante destacar que embora estejamos aqui dando ênfase a prática da capoeira na qualidade de jogo e a incidência do riso neste contexto, não se descarta possíveis incidências da capoeira como luta ou como jogo violento, acompanhados ou não do riso. O que quer dizer que o riso não pode ser considerando uma invariante na capoeira, embora este possa aparecer de forma provocada ou inusitada em qualquer situação, como discutiremos a seguir em 
quatro pontos que consideramos relevantes na discussão sobre o riso na Capoeira Angola.

\section{A presença simbólica do mestre}

Ao observarmos a presença do riso na roda Capoeira Angola não podemos deixar de mencionar que a qualidade e o caráter de seriedade é um importante componente regulador dessa performance ritual. Não a seriedade entendida como oposição ao riso e a graça, mas a seriedade em termos de comprometimento com suas tradições específicas, o que por vezes pode inibir a possibilidade do cômico.

O comprometimento dos capoeiras com a sua prática e com a roda, sobretudo no que diz respeito ao contexto da Capoeira Angola, se constrói a partir de uma noção de espiritualidade. Na roda de Capoeira Angola se cultiva a ancestralidade, seja a ancestralidade africana ou a da própria capoeira, isto é, as memórias de mestres antigos que contribuíram com a sua continuidade e permanência até os dias de hoje. Ademais, a musicalidade produzida pela bateria ${ }^{8}$ integra a roda viva, e o canto intensifica o momento ecumênico de louvação da capoeira.

A atmosfera de seriedade da roda de capoeira se acentua com a presença e/ou a representação simbólica da figura do mestre, tido como um grande pai, um superego que mesmo que não esteja presente será sempre lembrado direta ou indiretamente por intermédio de seus ensinamentos. Por um lado, o mestre representa uma possibilidade real de acesso ao contexto da capoeiragem, através de seus ensinamentos que estimulam uma certa autonomia e sentimento de

\footnotetext{
${ }^{8}$ A bateria da roda de Capoeira Angola é o conjunto de instrumentos musicais, composto atualmente por berimbaus, pandeiros, atabaque, agogô e reco-reco. A bateria da roda (também chamada de charanga ou orquestra) é a principal mantenedora da musicalidade na capoeira. As cantigas são invariavelmente interativas, já que há um diálogo ritualizado entre o "puxador" da cantiga e os demais integrantes da roda que, por sua vez, formam o "coro". Frequentemente, suas mensagens estão relacionadas com o que acontece na roda e sua relevância não está apenas nas mensagens embutidas em seus versos, mas na forma em que elas são executadas. Ao cantar, o capoeirista está também praticando uma ação comunicativa interativa que, certamente, é responsável pelo frenesi que, frequentemente, toma conta dos participantes de uma roda. Ou seja, elas obrigam os participantes a uma reação, estimulam comportamentos, difundem mensagens e valores e possibilitam a criação de novas situações. Canto e gesto corporal constituem, na capoeira, uma síntese integradora e que simultaneamente, um regula e é regulado pelo outro. Ver mais em Falcão (2004)
} 
pertencimento ao grupo, a roda e a capoeira. Por outro, o mestre também acaba por representar no imaginário dessa arte uma força moral, em certa medida inibidora, que opera, entre outras funções e relações, como mediadora do que é aceitável ou não dentro de uma roda de capoeira, pois como afirma Abib (2004, p. 66):

O mestre é aquele que é reconhecido por sua comunidade, como o detentor de um saber que encarna as lutas e sofrimentos, alegrias e celebrações, derrotas e vitórias, orgulho e heroísmo das gerações passadas, e tem a missão quase religiosa, de disponibilizar esse saber àqueles que a ele recorrem.

Como herdeira dos legados da malandragem, a Capoeira Angola carrega consigo uma ambiguidade em relação aquilo que é aceitável ou não, pois a malandragem, embora contemple a ideia de respeito, dá vazão ao exercício da falsidade, do tirar vantagem e da subversão às regras. Daí a importância da figura do mestre como regulador dos princípios de cada segmento organizado.

\section{O sorriso no rosto}

Na qualidade de performance, a roda de capoeira é um fenômeno que não dispensa audiência, tanto é que se apenas duas pessoas estiverem jogando isso não se configura como uma roda. Por outro lado, os espectadores da roda podem ser, e em geral o são, os próprios participantes, pois se trata de uma roda viva em que todos atuam de forma articulada. Ao constatarmos a propensão da roda de capoeira como um campo fértil para a existência do riso, e considerando-a como uma "espécie de gesto social", conforme ponderou Bergson (2004) acerca do riso, perguntamos: Na roda viva da Capoeira Angola, quem ri? De quem rir? Quem causa o riso?

O riso na roda de Capoeira Angola pode aparecer de forma espontânea e sincera entre os jogadores, mas sabe-se que o "sorriso no rosto" do angoleiro nem sempre configura uma expressão de sinceridade. Essa tática é, inclusive, estimulada e enaltecida como estratégia de jogo, já que a "falsidade" é uma das manhas da Capoeira Angola. O enganar, o ludibriar o outro demonstram controle 
da situação. Um bom exemplo disso podemos encontrar do relato oral do Mestre Bigo $^{9}$, discípulo de Mestre Pastinha, que traduz essa relação do sorriso com a falsidade, dizendo que se em uma situação de roda o dente do capoeira cair por conta de um golpe, este deve, sutil e prontamente, sair no aú, e com uma mão pegar o dente, encaixá-lo de novo na boca e sorrir para o camarada.

Tal qual realizado por figuras cômicas do teatro, especialmente por personagens-tipo da Comédia Dell'arte (Barni, 2003), como os arlequins, o sorriso com falsidade opera no sentido de instaurar um jogo brincante de astúcia entre os jogadores, com a capacidade de provocar um atordoamento, uma dubiedade da movimentação ou um falso-sentido da relação posta, isto é, o angoleiro tornase objeto do risível para provocar em seu adversário a dúvida sobre os seus próximos movimentos.

No processo de formação do capoeira é necessário enfrentar a vergonha, o medo, a exposição e a preocupação em como usar o corpo e os limites impostos pelas próprias condições e pelas condições impostas pelo outro jogador, questão que podem gerar nos neófitos e menos experientes a sensação de desafio e de desconforto. Nesse contexto, o riso opera como um privilégio dos capoeiristas mais experientes e seguros, que frequentemente riem de seus erros e dos erros daquele que tentou the "pegar" e não conseguiu e, ocasionalmente, dos mais ingênuos (crianças e iniciantes), capazes de simplesmente brincar, sem censuras.

\section{O riso sem risco}

Outra experiência na qual o riso se apresenta, cuja relevância é significativa para a roda de capoeira, tem a ver com os que se posicionam na beira da roda assistindo ao jogo (e invariavelmente participando da roda). Na condição de audiência-participante, são os responsáveis pelo riso mais espontâneo e que não oferece risco algum, pelo menos não naquele momento. Livre de qualquer pressão e embalada pelo ritmo das cantigas a audiência-participante ri com liberdade e à

${ }^{9}$ Mestre Bigo, também conhecido como Mestre Francisco 45 é Francisco Tomé dos Santos Filho, nasceu em 1946, no estado da Bahia. É líder da Academia de Capoeira Angola Ilê Axê, em São Paulo. 
vontade.

Frente a uma situação engraçada, o riso se irradia entre os participantes e assistentes. Já que, em geral, o riso é mesmo contagiante. Pois, conforme destaca Basques (2011, p. 113) retomando Bergson: "O riso precisará de eco por que será sempre o riso de um grupo, ao mesmo tempo em que esconde uma segunda intenção de entendimento, quase de cumplicidade, com outros ridentes, reais ou imaginários".

Como na capoeira existe subliminarmente um código de ética (aqui arriscamos chamar de a ética da malandragem), o limite entre uma situação engraçada e uma violência, em algumas circunstâncias, pode ser tênue o bastante para não ser compreendido por todos da mesma maneira. Por exemplo, em um jogo, um capoeirista para por alguns segundos na frente de outro com a guarda fechada, isto é, utilizando os braços como proteção, o que em tese o coloca numa situação de imunidade, todavia, o outro capoeirista ignora esse código gestual e se utiliza da força bruta para lançar uma chapa (golpe frontal desferido com a planta do pé) sobre a guarda do primeiro que, consequentemente, é lançado com a bunda no chão e as pernas para o ar. O que pode ser motivo de riso, porém o que provocou a queda, a depender do contexto, pode ser considerado como um sujeito violento. Assim, as situações passíveis de graça e de riso deliberado dependem dos acordos éticos e costumes de cada grupo ou roda, considerando que no contexto contemporâneo, a capoeira se organiza na lógica de grupos liderados por um ou mais mestres.

Um exemplo prático desse expediente pode ser encontrado na realização de uma conhecida ação ritualística da Capoeira Angola: a "Chamada de Angola" que, por sua vez, consiste em um momento do jogo em que os ataques e defesas são substituídos por uma espécie de encenação em que acontece um contato físico entre os jogadores, expondo-os a uma condição de maior vulnerabilidade. A Chamada de Angola, em geral, pode ser vista como uma estratégia para reorganizar o jogo ou testar o oponente. Embora não haja consenso no contexto geral da Capoeira Angola sobre a pertinência da utilização de golpes no momento de realização da Chamada, existe uma expectativa de que eles não sejam desferidos. 
Por outro lado, surpreender o oponente é algo aceitável na ética da malandragem presente na capoeira e também algo que incrementa e distingue o jogo dentro de sua perspectiva estética.

\section{O golpe certeiro e o fingimento: o elemento surpresa}

Por fim, o riso quase sempre aparece quando um dos jogadores é surpreendido por uma rasteira bem dada, por uma cabeçada certeira ou por um golpe qualquer que poderia ferir, nem tanto a integridade física, mas sobretudo a tão prezada moral do capoeirista.

$E$ do que se rir? De muitas peripécias que ocorrem durante o jogo. Por exemplo: Rir-se do encontro perfeito entre uma rasteira "bem dada", isto é, tecnicamente eficaz, e do jeito que o corpo do outro "deu” para cair (ou não cair) no chão. Rir-se de um faz de conta, de um deboche corporal, de um falso chilique, de um "embuste gestual" que, separados ou em conjunto, iludem e confundem o outro jogador. Isso pode ser observado nas performances de alguns capoeiristas, como, por exemplo, nas dos mestres Curió ${ }^{10}$ e Jogo de Dentro ${ }^{11}$, que habitualmente simulam tontura, transe, lesão ou embriaguez durante o jogo, deixando o oponente confuso e atônito para, subitamente partir para o ataque.

Rir-se quando em determinados momentos um jogador assume deliberadamente uma atitude circense fingindo que vai abrir os braços para louvar a Deus e mete a mão na cara do outro. Rir-se quando um jogador olha para trás do camarada com quem joga e aponta que alguém está lhe chamando, e este, ingenuamente, se vira para verificar e termina recebendo uma cabeçada ou outro golpe de alerta diante do descuido. Rir-se quando um jogador convida o outro para trocar um aperto de mão e, de repente, the aplica uma chapa "no bucho".

Embora essas sejam situações praticamente convencionadas de tão

${ }^{10}$ Mestre Curió é Jaime Martins dos Santos, nasceu em 1937, no estado da Bahia. É líder da Escola de Capoeira Angola Irmãos Gêmeos.

${ }^{11}$ Mestre Jogo de Dentro é Jorge Egídio dos Santos, nasceu em 19kk, no estado da Bahia. É líder do grupo Semente do Jogo de Angola. 
repetidas que já foram, quase sempre têm iniciantes numa roda de capoeira, quase sempre tem alguém que cai na brincadeira e termina arrancando risos da audiência-participante.

Conforme exposto anteriormente, o ritual da roda de capoeira envolve não só os dois jogadores que ocupam o centro da roda, mas também os capoeiristas dispostos ao redor e os que estão tocando instrumentos (a bateria), constituindo assim a roda viva, que influencia diretamente o jogo que se desenrola no centro da roda. A roda viva frente a uma situação de riso coletivo se desperta aguçando a curiosidade de todos os presentes que, numa espécie de simbiose, termina estimulando os jogadores a se empenharem ainda mais no jogo, chegando em alguns casos, a causar um frenesi coletivo e uma empolgação generalizada e contagiante.

Embora estejamos falando especificamente de Capoeira Angola, cumpre salientar que a presença do riso pode ocorrer com vigor em outras experiências de capoeira. Nesse sentido, podemos citar a existência de vertentes de capoeira que esteticamente e estruturalmente se assemelham à Capoeira Angola, mas que reivindicam uma prática de capoeiragem mais despojada, como é o caso de rodas de rua e do ascendente Movimento Novo.

O Movimento Novo surgiu no Rio de Janeiro em 2008 com o objetivo de promover o encontro de diferentes capoeiristas interessados em trocar experiências de jogo, sem maiores preocupações com questões relacionadas à identidade de grupos, tradições, hierarquias e comandos centralizados da roda. Por intermédio de registros em vídeos e divulgação no canal Youtube, o Movimento Novo ganhou muita projeção nacional e internacional.

Talvez pudéssemos afirmar que nesses contextos mais públicos e mais despojados, a presença do riso seja ainda mais proeminente já que se diminui o risco de censura que, como argumentamos anteriormente, pode estar posto, direta ou indiretamente, pela figura do mestre. Parece-nos que nas situações em que a figura reguladora do mestre se encontra mais dissipada ou diluída, as situações de riso estão diretamente relacionadas com jogos mais soltos e mais 
agressivos. No entanto, trata-se, na maior parte das vezes, de uma combatividade acordada entre os jogadores que gostam mesmo é do "mal feito", ou seja, de um “jogo pegado", para utilizar os jargões correntes no contexto da Capoeira Angola. Com frequência, nos jogos mais pegados os golpes vão às vias de fato e a roda viva ri das pernadas desenfreadas. Os golpes mais soltos exigem muita habilidade e autoconfiança dos jogadores, que por vezes arrancam de si defesas, saídas e contragolpes surpreendentes, também motivos de graça, pois a capacidade de surpreender, seja no ataque ou na defesa, continua sendo um grande feito dos jogadores que numa roda de capoeira se afirmam como herdeiros dos malandros da alvorada do Século XX.

\section{Considerações Finais}

Cumpre destacar que com essas considerações não pretendemos minimizar a importância do mestre de capoeira como pedagogo da arte da malandragem ao atribuí-lo a condição de regulador desta prática. Seu papel como mestre garante, no nosso entendimento, a consistência de uma estrutura capaz de tornar a capoeira uma prática que se consolida no coletivo, garantindo uma ética que dá vazão ao riso que juntamente com outras atitudes poderiam beirar a crueldade. Pois é importante notar que tanto o riso quanto a disputa podem desembocar em ações de crueldade. Por outro lado, não nos cabe idealizar e nem generalizar o papel do mestre ou da própria capoeira que se manifesta em suas particularidades e pluralidades.

O riso pode ser visto como uma chave de entendimento para melhor compreendermos e distinguir os saberes, as verdades, as crenças e os mitos na roda de Capoeira Angola. Nesta, as atividades consideradas "sérias" sistematicamente se transformam em atividades "de brincadeira" e isso pode desencadear situações de riso, que frequentemente decorrem de uma inadaptação ou distração particular dos sujeitos diante de condutas previsíveis.

Em geral, os capoeiras, na roda, experimentam no corpo uma ética e uma estética que dissimulam as formalidades da luta, ou seja, fingem lutar, dançando 
e jogando. Com isso, por meio da malícia e da surpresa, diluem o principal componente objetivo da luta que consiste no atacar e defender, e transformamna numa brincadeira descrita por alguns mestres como "perigosa". Assim, a Capoeira Angola se consolida na atualidade como uma prática sobretudo lúdica e em certa medida combativa, um campo fértil para a irrupção do riso coletivo e contagiante, que não resiste a um desajeitamento ou a uma troça.

Embora não seja apenas resultado de uma ação programada, o riso, pelo seu estreito vínculo com a alegria, a diversão e o prazer, é uma espécie de gesto social alçado à esfera do lúdico. Não por acaso que procedimentos risíveis são frequentemente requisitados e estimulados na roda de capoeira.

Como uma das expressões da condição humana, o riso tem na malandragem um esteio propício para se instaurar. A recorrência do riso não se dá a partir de uma perspectiva meramente técnica ou psicológica, mas primordialmente cultural, enfim, relacional.

\section{Referências}

ABIB, P. R. J. Capoeira Angola: cultura popular e o jogo dos saberes na roda. 2004. Tese (Doutorado em Educação) - Universidade Estadual de Campinas, Campinas, São Paulo, 2004.

ABREU, F. O barracão do mestre Waldemar. Salvador: Organização Zarabatana, 2003.

ALBERTI, V. O riso e o risível na história do pensamento. Rio de Janeiro: Jorge Zahar, 2011.

ALMEIDA, M. A. D. Memórias de um sargento de milícias. São Paulo: Klick, 1997.

BAKHTIN, M. A cultura popular na idade média e no renascimento: o contexto de François Rabelais. Trad. Yara Frateschi Vieira. 8a. ed. Brasília: Hucitec, 2013.

BARNI, R. A Loucura de Isabela e outras Comédias da Commedia Dell 'Arte. São Paulo: Iluminuras Ltda., 2003.

BASQUES, M. O riso como expressão de um modo de entendimento: do 
bergsonismo à antropologia. Scientiae Studia - Revista Latino-Americana de Filosofia e História da Ciência, São Paulo, 9, n. 1, p. 105-128, 2011. Disponível em: <https://doi.org/10.1590/s1678-31662011000100006>. Acesso em: 4 set. 2019.

BERGSON, H. O riso - ensaio sobre a significação da comicidade. Tradução de Ivone Castilho Benedetti. São Paulo: Martins Fontes, 2004.

BRUM, J. T. O riso e a jubilação. In: KANGUSSU, O. I., et al. O cômico e o trágico. Rio de Janeiro: 7Letras, 2008. Cap. 4, p. 56-58.

DAMATTA, R. A casa e a rua: espaço, cidadania, mulher e morte no Brasil. 5. ed. Rio de Janeiro: Rocco, 1997.

DIAS, A. A. Mandinga, manha \& malícia: uma história sobre os capoeira na capital da Bahia (1910-1925). Salvador: EDUFBA, 2006.

FALCÃO, J. L. C. O jogo da capoeira em jogo e a construção da práxis capoeirana. 2004.Tese (Doutorado em Educação) - Universidade Federal da Bahia, Salvador, 2004.

LIGIÉRO, Z. Malandro divino: a vida e a lenda de Zé Pelintra, personagem mítico da lapa carioca. Rio de Janeiro: Record, 2004.

MOREIRA, A. Canjiquinha: alegria da capoeira. Salvador: A Rasteira, 1989.

MURICY, C. Viva Pastinha. Ministério da Cultura do Governo Brasileiro, 52 min., 1999.

PANTANO, A. A. A personagem palhaço. São Paulo: UNESP, 2007.

PAVIS, P. Dicionário de Teatro. Trad. Maria Lúcia Pereira e Jacob Guinsburg. São Paulo: Perspectiva, 1999.

REIS, L. V. S. O mundo de pernas para o ar. a capoeira no Brasil. São Paulo: Publisher Brasil, 1997.

SALVADORI, M. A. B. Pedaços de uma sonora tradição popular (1890-1950). Universidade Estadual de Campinas. Campinas, São Paulo, 1990.

SILVA, R. L. Mandinga da rua: a construção do corpo cênico a partir de elementos da cultura popular urbana. 2005. Dissertação (Mestrado em Artes) - Universidade Estadual de Campinas, Instituto de Artes, Campinas, São Paulo, 2005. Disponível em: <http://www.repositorio.unicamp.br/handle/REPOSIP/284844>. Acesso em: 4 ago. 2019. 
Recebido em: 06/01/2020

Aprovado em: 30/03/2020

Universidade do Estado de Santa Catarina - UDESC Programa de Pós-Graduação em Teatro - PPGT Centro de Arte - CEART Urdimento - Revista de Estudos em Artes Cênicas Urdimento.ceart@udesc.br 